\title{
Enterprise Credit Risk Evaluation models: A Review of Current Research Trends
}

\author{
Ming-Chang Lee \\ Assistant professor of National Kaohsiung \\ University of Applied Sciences \\ 415 Chien Kung Road \\ Kaohsiung, Taiwan
}

\begin{abstract}
Enterprise Credit Risk becomes important issue in financial and accounting. It includes bankruptcy prediction, financial distress, corporate performance clustering / prediction and credit risk estimation. This research aims to provide a state-of-the art review of the relative literature and indicate relevant research opportunities. We found that the current research trends are necessary a method for reduction the feature subset, many hybrids SVM based model and rough model are proposed. Another consideration which requires future research is the evaluation of relative cost of Type I and Type $\Pi$ errors.
\end{abstract}

\section{Keywords}

Bankruptcy prediction, financial distress, corporate performance clustering / prediction, Credit risk estimation

\section{INTRODUCTION}

Credit risk assessment is an area of renewed interest in both the academic world and the business community [59]. Financial distress is a term in corporate finance used to indicate a condition when promises to creditors of a company are broken or honored with difficulty. Sometimes financial distress can lead to bankruptcy. Financial distress is usually associated with some costs to the company; these are known as costs of financial distress. Through financial distress lead to enterprise's bankruptcy, therefore financial distress is also called default risk. The financial crisis means that business enterprise loses the ability of payment, has no capability to play expired liability or expenses and appears asset value less than issued debt. Once the enterprise occur financial crisis, it will bring great loss for executive and financial institution. Financial distress prediction is of interest not only to managers but also to external stakeholders of company. For financial institutions, poor decision when granting credit to corporations in either losing potentially valuable clients or incurring substantial capital loss when the client subsequently defaults [16].

Enterprise financial distress or failure has been a focal point of issue in financial analysis. Use of financial data or financial ratio to predict enterprise financial distress / failure has been the major methodology for this research topic ([14], [23], [51], [63]). Financial distress prediction became a critical accounting and financial research area since 1960s in Europe and American.

Research on enterprise financial distress or failure and the application of its outcomes is a relative new research field. The aim of the present study is to provide a state-of-the art review about current research efforts in financial distress or failure. This review introduces the reader to specific topics concerning research objectives and method employed. This study tries to address the following questions:

- What are the specific financial application areas to evaluate the distress methods have been applied?

- What methods have been applied and to what extend. Do these methods outperform previous more traditional methods?

- What are the relative performance metrics considerations?

This study helps the researcher to avoid overlapping efforts and benchmark his/her practices against new developments Another aim of this study is to indicate fertile areas for further research work in the area.

\section{RELATIVE WOTK}

\subsection{Literature review}

Financial distress prediction become a critical accounting and finance research area since 1960s. Multiple discriminant analysis (MDA) developed a Z-score bankruptcy prediction and determine a outpoint Z-score (2.675) to classify healthy and distressed firms [1]. However, the MDA models assume the covariance matrices for two populations are identical and both populations need to be described by multivariate normal distribution [56]. If the assumptions regarding the identical covariance matrices and multivariate normal distribution are met, MDA is likely to be more efficient than Logistics regression [56]. Logistics regression is a form of linear regression. This model can predict a discrete outcome from a set of variables that may be continuous, discrete, dichotomous, or a mix of any of these. The first to apply the Logistic Regression model to financial distress prediction research was [45]. The conditional probability model becomes a popular technique in bankruptcy prediction domain [63]. The other researcher such as ([29], [36], [40]-[41]) studied the corporation credit default based on Logistics regression or risk model.

The non-parameter statistical analysis tool adopted in the literature about the financial crisis prediction was K-Nearest Neighbor approach (K-NN) ([22], [34]), Cluster analysis, these tools are trying to express the relationship among the variables 
by using the fuzzy measurement and through the $\alpha$ - cut process. The mathematical programming, discriminant analysis method and compare its performance with logistic regression, K-NN classifier and support vector machine technique is presented in [21]. The classification methods are binary classification methods in term of predictive and classification accuracy using fourteen datasets [71]. The classification accuracy of K-NN, support vector machine and neural network, without feature selection was explored by [33]. The results indicate that integrating these methods with effective feature selection approaches lead to more accurate classification.

Bayesian network (BN) models for early warning of bank failures was developed by [50]. They found that both a BN model and a composite attribute BN model have comparable performance to the well-known include decision tree classification algorithm. Some other techniques are Bayesian interface [24], Bayesian learning and Dempster-Shafer theory [46], Bayesian approach [53] and naïve Bayesian [3]. Unlike most regression techniques, BNs do not have any requirements on the underlying distributions of variables. BNs can easily model complex relationships among variables including partial mediators and interaction effects. BNs do not require complete information for observations.

Recently, the support vector machines (SVM) has been used in financial applications such as credit rating, time series prediction and insurance claim fraud detection. SVM is also used to financial distress prediction research [51]. For example, use SVM in Taiwan's issue credit rating system [13]. The credit scoring with a data mining approach based on SVM is presented in [19]. Some research are integration of two approaches, such as [31], they studied prediction model building with clustering - launched classification and support vector machines in credit scoring, [20] studied credit rating analysis with support vectors machine and neural networks: a market comparative study. Some other techniques, such as kernel learning methods [65], Least squares support vector machine ensemble models [69], hybrid support SVM ([9], [14], [26]) used support vector machines for default prediction of SMEs based on technology credit.

The theory of rough sets has emerged as another method for dealing with uncertainty using from inexact or incomplete information [47]. Predicting financial distress /failure are developed due to the advantage of computer and information science, such as neural networks, decision tress and rough sets approach ([15], [42]). Rough sets are a new technique for data mining domain application. A new rough set model based on database systems is presented in [18]. in probabilistic rough sets, ([60], [61]) used fuzzy sets in the probabilistic rough set model and fuzziness in probabilistic rough sets. Some other techniques, such as neural- fuzzy [58], integrating fuzzy rule and K-NN method [28], optimized fuzzy classifier [30], fuzzy markov model [38], and multi-criteria fuzzy logic [64].

Decision tree is a classification and predication and prediction method, which successively divides observations into mutually exclusive subgroup. A decision diagrams in machine learning to empirical study on real-life credit risk data is presented in [43]. In predict business failure, [37] used classification and regression tree. Some other techniques, such as [68] used multi-objective genetic programming approach to developing Pareto optimal decision tree, [39] applied machine learning techniques and statistical models to determine insurers rating.

Survival analysis (SA) was originally developed for studying time from commencement treatment until depth. SA can predict the time until the event will occur instead of predicting the probability of occurrence an event. SA application in credit scoring, such as Survival analysis methods for personal loan data [54], Reject interface in credit operation [52], Corporate credit risk model and the macroeconomy [7], modeling probability using survival combination scores [2] and Modeling consumer credit risk via survival analysis [6].

From the early 2000s, some other credit scoring modeling techniques were also employed in the bankruptcy prediction research area and have shown good performance. This model is called soft-computing, including the Rough Sets approach [42], Grey Relational Evaluation, Genetic algorithm with K-NN (k-nearest neighbor) and Genetic algorithm with Neural Network [35]. The artificial neural network vs. linear discriminant analysis in credit rating forecast was to comparative study of predication performance [27]. There are ongoing efforts during the past decade to integrate fuzzy logic, artificial neural network (ANN), and genetic algorithm (GA) to build efficient systems in soft computing paradigm [5].

Hybrid model are credit scoring models which are developed by integrating two or more existing model. This type of methods is difficult to formulate and implement than simple methods. Apply the neural network and multivariate discriminate analysis model to financial distress prediction research [44]. ([48], [57]) used the neural network, multivariate discriminate analysis Logistic model and decision tree to financial distress prediction research. The intelligent techniques contain rough sets, soft computing, NN, Fuzzy logic, CBR, and decision tree. For example, [32] used a two-stage hybrid credit scoring model using artificial neural networks and multivariate adaptive regression spines. In combination of two model, [70] used Rough set theory and GA-based SVM to evaluate credit risk. Some other techniques, such as integrating genetic programming and support vector machine [67], A intelligent system for credit risk evaluation [66], Combination of feature selection approaches and SVM.

\subsection{Enterprise financial status index}

The financial comprehensive evaluation refers to analyze the financial situation and management achievement of the company by using the financial indicators that are reflected in the financial report. In financial reporting analysis, which have five factors for enterprise financial failure [17]. The measured attribute are financial structure, earning ability, debt paying ability, operation ability and cash flow. 
TABLE 1. Enterprise financial status indictor

\begin{tabular}{|c|c|}
\hline & Financial distress index \\
\hline \multirow[t]{3}{*}{ Financial structure } & Debt ratio \\
\hline & Stockholder / total assets \\
\hline & EPS (earning per share) \\
\hline \multirow[t]{4}{*}{ Earning ability } & :ROA (Return on total assets) \\
\hline & ROE (Return on Stockholders equity) \\
\hline & Profit margin \\
\hline & Earning per share \\
\hline \multirow[t]{5}{*}{ Operating ability } & Fixed Assets turnover ratio \\
\hline & Account receivable turnover ration \\
\hline & Average collection period \\
\hline & :Inventory turnover ratio \\
\hline & Average days to sell the Inventory \\
\hline \multirow[t]{3}{*}{ Debt paying ability } & Current ratio \\
\hline & Quick ratio \\
\hline & Time interest earned \\
\hline \multirow[t]{3}{*}{ Cash flow } & Cash flow ratio \\
\hline & Cash flow adequacy ratio \\
\hline & Cash flow reinvestment ratio \\
\hline \multirow[t]{5}{*}{ Growth } & Revenue growth ratio \\
\hline & Stockholder's equity growth ratio \\
\hline & Total assets turnover growth ratio \\
\hline & Income from operation growth ratio \\
\hline & Earning before taxes growth ratio \\
\hline
\end{tabular}

TABLE 2. Enterprise credit risk mode

\begin{tabular}{|c|c|c|}
\hline Category & Area & Some Approach \\
\hline \multirow[t]{2}{*}{ Statistical model } & $\begin{array}{l}\text { Parametric Statistical } \\
\text { Method }\end{array}$ & $\begin{array}{l}\text { 1. Discriminant analysis } \\
\text { 2. Linear multi discriminant analysis } \\
\text { 3. Logistic regression } \\
\text { 4. Bayesian risk Discriminant analysis }\end{array}$ \\
\hline & $\begin{array}{l}\text { Non-Parametric Statistical } \\
\text { Method }\end{array}$ & $\begin{array}{l}\text { 1. K- nearest neighbor } \\
\text { 2. Cluster analysis }\end{array}$ \\
\hline Neural Networks & Machine learning & $\begin{array}{l}\text { 1. Multilayer perception } \\
\text { 2. Back propagation } \\
\text { 3. Radial function neural network } \\
\text { 3. Probabilistic neural network } \\
\text { 4. Self-organized competition }\end{array}$ \\
\hline $\begin{array}{l}\text { Learning } \\
\text { vector }\end{array}$ & Machine learning & Support Vector Machine \\
\hline Soft-computing & Reduction attributes & $\begin{array}{ll}\text { 1. } & \text { Rough sets of reduction knowledge } \\
\text { 2. } & \text { Grey relational of reduction knowledge } \\
\text { 3. } & \text { Genetic algorithm of reduction knowledge } \\
\text { 4. } & \text { Fuzzy-Rough Sets Approach } \\
\end{array}$ \\
\hline $\begin{array}{l}\text { Survival analysis } \\
\text { (SA) }\end{array}$ & Time to event data analysis & $\begin{array}{l}\text { 1. Credit risk modeling based on SA } \\
\text { 2. Corporate credit risk and the macro economy }\end{array}$ \\
\hline Hybrid models & $\begin{array}{l}\text { Combination of two or more } \\
\text { techniques }\end{array}$ & $\begin{array}{ll}\text { 1. } & \text { Rough - K Nearest Neighbor } \\
\text { 2. } & \text { Rough Sets - Neural Network } \\
\text { 3. } & \text { Fuzzy-Rough Sets - Nearest Neighbor } \\
\text { 4. } & \text { Fuzzy- Nearest Neighbor } \\
\text { 5. Support Vector Machine with Nearest Neighbor } \\
\text { 6. } \\
\text { 7. } & \text { Ant Colony Algorithm based on quick-reduct algorithm }\end{array}$ \\
\hline
\end{tabular}




\section{THE METHODS OF CTRDIT RISK MODEL}

The methods of enterprise credit risk modes include statistical model, neural network, learning vector, soft-computing, and hybrid models. Table 2 denoted as enterprise credit risk model. Popular methods that will be mentioned in study are Neural networks, Bayesian classifier, Discriminant analysis, Logistic regression, K-nearest neighbor, Decision tree, Case base reasoning, Support vector machine, Software computing, Fuzzy rule-based system, Generic algorithms, Grey relation, and Hybrid models.

\section{$\odot$ Neural network:}

Neural networks are mathematical representations inspired by the functioning of human brain. Many type of neural networks have been suggested in the literature of both supervised and unsupervised learning. They are powerful tools for unknown data relationship modeling. Neural networks able to recognize the complex pattern between input and output variables then predict the outcome of new independent input data. The advantage of $\mathrm{NN}$ is that they act as black boxes as it is difficult to humans to interpret the way $\mathrm{NN}$ reach their decision. Another criticism on $\mathrm{NN}$ is that a number of parameters like the network topology must be defined empirically. However, algorithms have been proposed to extract comprehendible rules from $\mathrm{NN}$.

\section{OSurvival analysis}

Survival analysis is a branch of statistics which deals with death in biological organisms and failure in mechanical systems. This topic is called reliability theory or reliability analysis in engineering, and duration analysis or duration modeling in economics or sociology. This is a new credit scoring model. The conventional method can distinguish good borrowers from bed ones at the time of load application, but this model can compute probability of the customer over the customers' lifetime and perform profit scoring.

\section{$\odot$ Bayesian classifier}

A Bayes classifier is a simple probabilistic classifier based on applying Bayes' theorem with strong (naive) independence assumptions. A more descriptive term for the underlying probability model would be "independent feature model". Depending on the precise nature of the probability model, Bayes classifiers can be trained very efficiently in a supervised learning setting. In many practical applications, parameter estimation for Bayes classifier uses the method of maximum likelihood; in other words, one can work with the Bayes classifier without believing in Bayesian probability or using any Bayesian methods. The major disadvantage of this model is that the predictive accuracy is highly correlated with this assumption. An advantage of this method is that it requires a small amount of training data to estimate the parameters (mean and variances of the variables) necessary for classification.

$\odot$ Discriminant analysis
Linear discriminant analysis (LDA) studied by Fisher's is an alternative to logistic regression that assume the explanatory variables follow a multivariate normal distribution and have a common variance-covariance matrix. This method is used to classifying observation in two classes. The objective of this method is to minimize the distance within each group and maximize the distance between different groups using discriminant function.

\section{$\odot$ Logistic regression}

Logistic regression is used for prediction of the probability of occurrence of an event by fitting data to a logistic function. It is a generalized linear model used for binomial regression. Like other forms of regression analysis, it makes use of one or more predictor variables that may be either numerical or categorical. Logistic regression is used extensively in the medical and social sciences fields, as well as marketing applications such as prediction of a customer's propensity to purchase a product or cease a subscription. The advantages of this method are that logistic regression does not assume linearity of relationship between the independent variables and the dependent, does not require normal distribution variables and the weakness of the model is that the independent variables be linearly related to the $\log$ it of dependent variable.

\section{$\odot$ K-nearest neighbor}

K-NN classification for test set from training set. For each row of the test set, the k nearest (in Euclidean distance) training set vectors are found, and the classification is decided by majority vote, with ties broken at random. If there are ties for the kth nearest vector, all candidates are included in the vote. $\mathrm{K}-\mathrm{NN}$ is a type of instance-based learning, or lazy learning where the function is only approximated locally and all computation is deferred until classification. For each new observation this method explores the pattern space for the K-NN that are closet to the new observation in term of distance between the explanatory variable. The new observation is assigned to the class which its most K-NN belong to that class.

\section{$\odot$ Decision tree}

A decision tree is a decision support tool that uses a tree-like graph or model of decisions and their possible consequences. Decision trees are commonly used in operations research, specifically in decision analysis, to help identify a strategy most likely to reach a goal. Top node in this tree is the root node which a decision is supposed to take on it. In each inner node, it is done a test on an attribute or input variable. Each branch which follows that node lead to the result of the test, and the classes are represented by left nodes. Classification trees are used when the response variable is quantitative discrete or qualitative. The advantage of this method is that it is a white box model and so it is simple to understand and explanation, but the limitation of this model is that, it can not be generalized a designed structure for one context to the other contexts.

$\odot$ Case base reasoning

Case-based reasoning (CBR), broadly construed, is the process 
of solving new problems based on the solutions of similar past problems. Key issues in CBR are the similarity measure and the retrieval of similar case. Popular matching techniques are K-NN, inductive learning and knowledge guide. K-NN assesses the similarity of two cases by calculating their Euclidean distance. This approach assumes that all features are equally relevant. Since this is not always in the case, improved algorithms introducing weighted features have been proposed.

\section{$\odot$ Support vector machine}

Support vector machine (SVM) is a powerful learning algorithm based on recent advances in statistical learning theory. SVM is learning systems that use a hypothesis space of linear functions in a high-dimensional space, trained with a learning algorithm from optimization theory that implements a learning bias derived from statistical learning theory. SVM has recently become one of the popular tools for machine learning and data mining and can perform both classification and regression. SVM uses a linear model to implement non-linear class boundaries by mapping input vectors non-linearly into a high-dimensional feature space using kernels. The training examples that are closet to the maximum margin hyperplane are called support vectors. The support vectors are then used to construct an optimal linear separating hyperplane or a linear regression function in this feature space. The advantages of this method are that, in the nonparametric case, SVM requires no data structure assumptions such as normal distribution and continuity. The weaknesses of this method are that, it is difficult to interpret uncle the features interpretable and standard formulation do not contain specification of business constraints.

\section{$\odot$ Rough set theory}

Rough set was introduced by [47]. Rough set theory can be regarded as a new mathematical tool for imperfect data analysis. The theory has found applications in many domains, such as decision support, engineering, environment, banking, medicine and others. Rough set is a formal approximation of a crisp set (i.e., conventional set) in terms of a pair of sets which give the lower and the upper approximation of the original set. In the standard version of rough set theory, the lower- and upper-approximation sets are crisp sets, but in other variations, the approximating sets may be fuzzy sets.

$\odot$ Fuzzy rule-based system

Fuzzy rule-based system: It helps to creditors in designing rules that accurately derive the credit score with explanation, while most of credits scoring models focus on estimating a score without explanation how the results obtained. The advantages of this model are that the fuzzy rules are capable of handling both quantitative and qualitative factors, so if there are a large set of inputs, scoring results will be less sensitive to small measurement errors [25].

\section{$\odot$ Generic algorithms}

Genetic algorithm (GA) is a search heuristic that mimics the process of natural evolution. This heuristic is routinely used to generate useful solutions to optimization and search problems. Genetic algorithms belong to the larger class of evolutionary algorithms (EA), which generate solutions to optimization problems using techniques inspired by natural evolution, such as inheritance, mutation, selection, and crossover.

\section{$\odot$ Hybrid models}

Hybrid models are credit scoring models which are developed by integrating two or more existing models [55]. The advantage of these models is that the creditor can benefit from the advantages of two or more methods and also they can remove the weakness of a model by combination them with the other models, but this type of models are difficult to formulate and implement than simple methods [25].

\section{FUTURERESEARCH ISSUES}

There are many fertile areas of future research. Most of researches seem to prefer the neural network method. Since to improve the performance of this method, it is necessary a method for reduction the feature subset such as rough sets, many hybrid SVM based model are proposed. Rough sets are an effective mathematical analysis tool to deal with vagueness and uncertainty in the area of area of decision analysis. Rough sets theory is applied for rule extractions reduction on (fuzzy) information system without lose their information.

The basic accuracy is computed as the proportion of correct classifications or prediction. Type Ierror as the number of 'actually poor performance banks' predicted as 'adequate performance banks' expressed as percentage of total poor performance banks and Type II error as the number of 'actual adequate performance banks' predicted as 'poor performance banks' expressed as a percentage of total adequate performance banks. The objective of this present study is primarily to develop a new hybrid architecture in the soft computing paradigm to achieve low Type Ierror as well as high overall accuracy for small community banks. From the business perspective, Type Ierror is more detrimental than Type II error. Thus a good prediction model should have lower Type Ierror.

A future research direction may be the development and application of soft computing and hybrid models. Soft Computing became a formal Computer Science area of study in early 1990's. Earlier computational approaches could model and precisely analyze only relatively simple systems. More complex systems arising in biology, medicine, the humanities, management sciences, and similar fields often remained intractable to conventional mathematical and analytical methods That said, it should be pointed out that simplicity and complexity of systems are relative, and many conventional mathematical models have been both challenging and very productive. Soft computing deals with imprecision, uncertainty, partial truth, and approximation to achieve practicability, robustness and low solution cost. Components of soft computing include:

- $\quad$ Fuzzy systems (FS)

- Evolutionary computation (EC), including: Evolutionary algorithms, Harmony search 
- Swarm intelligence

- Ideas about probability including: Bayesian network

- Chaos theory

- Perception

Soft computing techniques resemble biological processes more closely than traditional techniques, which are largely based on formal logical systems, such as sentential logic and predicate logic, or rely heavily on computer-aided numerical analysis (as in finite element analysis). Soft computing techniques are intended to complement each other [49].

In order to develop a robust prediction system, a number of models taken from neural networks, statistics, decision tree, generic algorithms, case base reasoning, Support vector machine, bayesian classifier, and fuzzy rule based classifier will have to be seamlessly integrated, implemented, tested and validated. Support vector classification technique based on the idea of structure risk minimization. Fuzzy set are capable in corporate data. Thus, using the advantage of machine learning and fuzzy sets prediction accurate implemented for analyzing predictors as financial ratios. [8] and [59] used fuzzy support vector machine for bankruptcy prediction. [4] used neural network rule extraction and decision table for credit-risk evaluation. [12] integrate of decision tree classification and logistic regression for prediction corporate financial distress.

\section{CONCLUSION}

Bankruptcy prediction seems to be popular topic of the application of data mining techniques on financial data. Corporate bankruptcy causes economic damages for management, investors, creditors and employees together along with social cost. For these reasons bankruptcy predict, credit scoring is an important issue in finance. In this research we review the paper which had applied statistic model, neural networks, learning vector, software-computing and hybrid model in credit risk problem. We research almost all paper which focused on methods from 2003 to 2011 . We found that (1) the specific applications areas include in the field of auditing refer to bankruptcy prediction, financial distress, management fraud, and corporate performance prediction. (2) Most of researches seem to prefer the neural network method. (3) Since to improve the performance of this method, it is necessary a method for reduction the feature subset, many hybrids SVM based model and rough model are proposed. (4) Another consideration which requires future research is the evaluation of relative cost of Type Iand Type Ierrors. (5) We propose the models which have the ability of estimation the probability of default, and also are simple to interpret and understand. (6) Survival analysis will be a new credit scoring model.

\section{ACKNOWLEDGMENT}

I would like to thank the anonymous reviewers for their constructive comments on this paper

\section{REFERENCES}

[1] Altman, E. I., "Financial Ratios, Discriminant analysis and the prediction of corporate bankruptcy", Journal of Finance, Vol. 23, No. 4, 1968, pp.589-609

[2] Andreeva , G., Ansell, J., and Crook, J., Modeling probability using survival combination scores", Europen Journal of Operational Research, Vol. 183, No. 3, 2007, pp. 1537-1549.

[3] Antonakis, A. C. and Sfakianakis,M. E., "Assessing naïve Bayes as a method of screening credit applications", Journal of applied Statistics, Vol. 36, No. 5, 2009, pp 537-545

[4] Baesens, B., Setiono, R., Muse, C., and Vanthienen, J., "Using Neural network rule extraction and decision tables for credit-risk evaluation", Management Science, Vol. 49, No. 3, 2003, pp. 312-329.

[5] Bian, H. and Mazlack, L., "Fuzzy-rough nearest-neighbor classification approach", 22nd International Conference of the North American, 24-26 July, 2003.

[6] Cao, R. Vilar, J. M. and Devia, A., "Modeling consumer credit risk via survival analysis", Statistics \& Operational Research Transactions, Vol. 33, No. 1, 2009, pp. 3-30.

[7] Carling, K. Jacobson, T., Linde, J., and Roszbach, K., "Corporate credit risk modeling and the Macroeconomy", Journal of Banking \& Finance, Vol. 31, No. 3, 2007, pp. 845-868

[8] Chaduhuri, A, and De, K., "Fuzzy support vector machine for bankruptcy prediction", Applied Soft Computing, Vol. 11, No. 2, 2011, pp.2472-2486.

[9] Chen W. Ma, C. and Ma, L., "Mining the customer credit using hybrid support vector machine techniques", Expert Systems with Application, Vol. 36, No. 4, 2009, pp. 7611-7616.

[10] Chen, D., "Using neural networks and data mining techniques for financial distress prediction model", Expert Systems with Application, Vol. 36, No. 2, 2009, pp.4075-4086

[11] Chen, F. L. and Li, F. C., "Combination of feature selection approaches with SVM in credit scoring", Expert Systems with Application, Vol. 37, No. 7, 2010, pp. 4902-4909.

[12] Chen, M. Y., Prediction corporate financial distress based on integration of decision tree classification and logistic regression, Expert Systems with Application, Vol. 38, No. 9, 2011, pp.11261-11272.

[13] Chen, W. H. and Shin, J. Y., "A study of Taiwan's issuer credit rating systems using support vector machine", Expert Systems with Application, Vol. 30, No. 3, 2006 , pp. 427-435.

[14] Cheng, J. U., Yeh, C. H. and Chiu, Y. W., "Improving business failure prediction using rough sets with Non-financial variables", LNCS, Vol. 4431/2007, 2007, pp. 614-621.

[15] Dimitras, A. L., Slowinski, R., Susmaga, R. and Zopounidis, C., "Business failure Prediction using rough sets", European Journal of Operational Research, Vol. 114,1999 , pp. $263-280$ 
[16] Gestel, T. V., Baestens, b., Suykens, J., and Poel, D. V., "Bayesian kernel based on classification for financial distress detection", European Journal of operational Research, Vol. 172, 2006, pp. 979-1003.

[17] Gibson, C. H., "Financial Reporting and Analysis: Using Financial Associating Information", South-Western College Pub, 10 editions, April, 27, 2006

[18] Hu, X. T., Lin,T. Y. and Han, J., "A new rough sets model based on database systems", Lecture Notes in Artificial intelligence, Vol. 2639, 2003, pp. 114-121

[19] Huang, C. L., Chen, M. C., and Wang, C. J., “ Credit scoring with a data mining approach based on support vector machines", Expert Systems with Applications, Vol. 33, No. 4, 2007, pp. 847-856.

[20] Huang, Z., Chen, H., Hsu, C. J., Chen, W. H. and Wu, S., "Credit rating analysis with support vector machines and neural networks: a market comparative study", Decision Support Systems, Vol. 37, No. 4, 2004, pp. 543-558.

[21] Ince, H. and Aktan, B., "A comparison of data mining techniques for credit scoring in banking: a managerial perspective", Journal of Business Economics and Management, Vol. 3, No. 2, 2009, pp. 233-240

[22] Islam, M. J., Wu, Q. M. J., Ahmadi, M. and Sid-Ahmed, M. A., "Investigating the performance of Naïve- Bayes Classifier and K-NN classifiers", International Conference on Convergence Information Technology, IEEE Computer Society. 2007.

[23] Jayanth, J., Suresh, Joseph. K., Vaishnavi, J., "Bankruptcy prediction using SVM and Hybrid SVM Survey", International Journal of Computer Application, Vol. 34, No. 7, 2011, pp. 39-45

[24] Kadam, A. and Lenk, P., "Bayesian interface for issuer heterogeneity in credit rating migration", Journal of Bank \& Finance, Vol. 32, No. 10, 2008, pp. 2267-2274.

[25] Keramati, A. and Yousefi, N., "A propose classification of data mining techniques in credit scoring", Proceeding of the 2011 international Conference of Industrial Engineering and Operations Management, Kuala Lumpur, Malaysia, January 22-24, 2011

[26] Kim, H. and Sohin, S. Y., "Support vector machines for default prediction of SMEs based on technology credit", European Journal of Operational Research, Vol. 201, No. 3, 2010, pp. 838-846.

[27] Kumar, K. and Bhattacharya, S., "Artificial neural networks vs linear discriminant analysis in credit ratings forecast: a comparative study of prediction performances", Review of Accounting and Finance, Vol. 3, No. 3, 2006, pp. 216-227

[28] Laha, A., "Building contextual classifier by integrating fuzzy rule based classification techniques and K-NN method for credit scoring", Advanced Engineering Informatics, Vol. 21, No. 3, 2007, pp. 281-291.

[29] Laitinen,E. K., "Predicting a corporate credit analyst's risk estimate by logistic and linear models", International Review of Financial Analysis, Vol. 8, No. 2, 1999, pp. 97-121.

[30] Lashsasna, A., Ainon, R. N. and Wah, T. Y.,"Credit risk evaluation decision modeling through optimal fuzzy classifier", International Symposium on Information technology. IEEE Computer Society, 2008.

[31] Lau, S. T., Cheng, B. W., and Hsieh, C. H., “ Prediction model building with clustering-launched classification and support vector machines in credit scoring", Expert Systems with Applications, Vol. 36, No. 4, 2009, pp. 7526-7556.

[32] Lee, T. S., and Chen, I. F.,"A two-stage hybrid credit scoring model using artificial neural networks and multivariate adaptive regression splines", Expert Systems with Applications, Vol. 28, No. 4, 2005, pp. 743-752.

[33] Li, F. C., "The hybrid credit scoring model based on K-NN classifier", Sixth International Conference on Fuzzy Systems and Knowledge Discovery, IEEE Computer Society, 2009.

[34] Li, F. C., "Comparison of the Primitive classifiers without features selection in credit scoring", International Conference on Management and Service Science, 20-22 Sept. 2009, pp. 1-5.

[35] Li, T. S., "Feature Selection for Classification by Using a GA-Based Neural Network Approach", Journal of the Chinese Institute of Industrial Engineering, Vol. 23, No. 1, 2006, pp. 55-64.

[36] Liang, Y. and Xin, H., "Application of Discretization in the use of Logistic Financial Rating", International Conference on Business Intelligence and Financial Engineering, 24-26 July 2009, pp. 364-368.

[37] Liu, H., Sun, J., and Wu, J., "Predicting business failure using classification and regression tree: An empirical comparison with popular classical statistical methods and top classification mining methods", Expert Systems with Applications, Vol. 37, No. 8, 2010, pp. 5895-5904.

[38] Liu, K., Lai, K. K., and Guu, s. M., "Dynamic credit scoring on consumer behavior using Fuzzy Markov model", Fourth International Multi-Conference on Computing in the Global Information Technology. IEEE Computer Society, 2009.

[39] Lopez , R. F., "Modeling of insurers' rating determinants. An application of machine learning techniques and statistical models", European Journal of Operational Research, Vol. 183, No. 2., 2007, pp.1488-1512.

[40] Luo, J. and Lei, H. y. ," Empirical study of corporation credit default probability based on logistic model", Wireless communication, networking and Mobile computing, 4th conference on WICON 08, 12-14 Oct. 2008, pp. 1-8.

[41] Ma, R. W. and Tang, C. Y., "Building up default predicting model based on logistic model and misclassification loss", Systems Engineering- Theory \& Practice, Vol. 17, No. 8, 2007, pp. 33-38.

[42] McKee, T. E., "Rough sets bankruptcy prediction models virus auditor signaling rates", Journal of Forecasting, Vol. 22, No. 8, 2003, pp. 569-586

[43] Mues, C. Baesens, B., Files, C. M., and Vanthienen, J., "Decision diagrams in machine learning: an empirical study on real-life credit-risk data”, Expert Systems with 
Applications, Vol. 27, No. 2, 2004, pp. 257-264.

[44] Odom, M., Sharda, R.," A neural network model for bankruptcy prediction", IEEE INNS International Joint Conference on Neural Networks, Vol. 12, 1990, pp.163-168.

[45] Ohlson , J. A., "Financial ratios and the probabilistic prediction of bankruptcy", Journal of Accounting Research, Vol. 18, No. 1,1980, pp. 109-131

[46] Panigrshi, S. Kundu, A, Sural, S. and Majumder, A. K., "Credit card add fraud detection: a fusion approach using Dempster-Shafer theory and Bayesian learning", Information Fusion, Vol. 10, No. 4, 2009, pp. 354-363.

[47] Pawlak, A., "Rough sets", International Journal of Information and Computer Sciences, Vol. 11, No. 3, 1982, pp. 341-356

[48] Ravi Kumar, P. and Ravi, V., "Bankruptcy prediction in banks and firms via statistical and intelligent techniques A review", European Journal of Operation Research, vol. 180, No. 1, 2007, pp. 1-28

[49] Ravi, V., Kurniawan, H., Thai, P. N. K., and Ravi Kumar, P., "Soft computing system for bank performance prediction", Applied Soft Computing, Vol. 8, No. 1, 2007, pp. 305-315.

[50] Sarkar, S., and R. S. Sriram., "Bayesian Models for Early Warning of Bank Failures", Management Science, Vol. 47, No. 11, 2001, pp.1457-1475.

[51] Shin, K. S., Lee, T. S. and Kim, H. J., ,"An application of support vector machines in bankruptcy prediction model", Expert system Application, Vol. 28, No. 1, 2005, pp. 127-135

[52] Sohn , S. Y.and Shim,H. W.,"Reject inference in credit operations based on survival analysis", Expert Systems with Applications, Vol. 31, No. 1, 2006, pp. 26-29.

[53] Stefanescu, C. Tunaru, R., and Tunbull, S., "The credit rating process and estimation of transition probabilities: a Bayesian approach", Journal of Empirical Finance, Vol. 16, No. 2, 2009, pp. 216-234.

[54] Stepanova, M. and Thomas, L. C., "Survival analysis methods for personal loan data", Operations Research, Vol. 50, No. 2, 2002, pp. 277-289.

[55] Sun, J. and LI, H. L., "Financial distress prediction based on serial combination of multiple classification", Expert Systems with Application, Vol. 36, No. 4, 2009, pp.8659-8666

[56] Tabachnick, B. G. and Fidell, L. S., "Using Multivariate Statistics", Allyn and Bacon Press, UK. 2000

[57] Tam , K. Y. and Kiang, M., "Managerial applications of neural network: the case of bank failure predictions", Management Sciences, Vol. 38, 1992, pp.927-947

[58] Tung, W. L., Quek, C., Cheng, P. and EWS, G., "a novel neural-fuzzy based early warning system for predicting bank failures", Neural Networks, Vol. 17, No.4, 2004,pp. 567-587.
[59] Wang, Y., Wang, S. and Lai, K. K., "A new fuzzy support vector Machine to evaluate credit risk", IEEE Transactions Fuzzy Systems, Vol. 13, No. 6, 2005, pp. 820-831

[60] Wei , L. L. and Zhang, W. X., "Probabilistic rough characterized by Fuzzy Sets", Lecture Notes in Artificial Intelligence, 2369, 2003, pp. 173-180

[61] Wong, S. K.M., Zialo, W. and Li, Y. R., "Comparison of rough set and statistical methods in inductive learning", International Journal of Man-Machine Studied, Vol. 24, 1986, pp. 53-72

[62] Wu, C Y., "Using non-financial information to predict bankruptcy: A study of public companies in Taiwan", International Journal of Management, Vol. 21, No. 2, 2004, pp. 194-202

[63] Xiao, Z., Yang, X., Pang, Y. and Dang, X., "The prediction for listed companies' financial distress by using multiple prediction network with rough set and Dempster -Shafer evidence theory", Knowledge - Based Systems, Vol. 26, 2012, pp. 196-206.

[64] Xinhui , C. and Zhong, Q., " Consumer credit scoring based on multi-criteria fuzzy logic", International Conference on Business Intelligence and Financial Engineering. IEEE Computer Society. 2009.

[65] Yang, Y., "Adaptive credit scoring with kernel learning methods', European Journal of Operational Research, Vol. 183, No. 3, 2007, pp. 1521-1536.

[66] Yu,L., Wang, S., Wen, F., Lai, K. K., and He, S., "Designing a hybrid intelligent mining system for credit risk evaluation', Journal of Systems Science and Complexity, Vol. 21, No. 4, 2008, pp. 527-539.

[67] Zhang, D., Hifi, M. Chen, Q. and Ye, W., "A hybrid credit scoring based on genetic programming and support vector machine", 4th International Conference on Natural Computation, IEEE Computer Society, 2008, pp. 8-12

[68] Zhao, H, "A multi-objective genetic programming approach to developing Pareto optimal decision tree", Decision Support Systems, Vol. 43, No. 3, .2007, pp. 809-826.

[69] Zhou, L., Lai, K. K., and Yu, L., "Least squares support vector machines ensemble models for credit scoring", Expert Systems with Applications, Vol. 37, No. 1, 2010, pp. 127-133.

[70] Zhou, J. and Bai, T., "Credit risk assessment using rough set theory and GA-based SVM", The 3rd International Conference on Grid and Pervasive ComputingWorkshops, IEEE Computer Society Kunming, 2008, pp. 320-325.

[71] Zhou, L. and Lai, K. K. and Yu, L., "Credit scoring using support vector machine with direct search for parameters selection", Soft Computing, Vol. 13, No. 2, 2009, pp. 149-155. 